Open Access

\title{
Hyperoxia provokes a time- and dose- dependent inflammatory response in mechanically ventilated mice, irrespective of tidal volumes
}

Hendrik J. F. Helmerhorst ${ }^{1,2,3^{*}}$, Laura R. A. Schouten ${ }^{3,4}$, Gerry T. M. Wagenaar ${ }^{5}$, Nicole P. Juffermans ${ }^{3,4}$, Joris J. T. H. Roelofs ${ }^{6}$, Marcus J. Schultz ${ }^{3,4}$, Evert de Jonge ${ }^{1}$ and David J. van Westerloo ${ }^{1}$

\author{
* Correspondence: \\ H.J.F.Helmerhorst@lumc.nl \\ ${ }^{1}$ Department of Intensive Care \\ Medicine, Leiden University Medical \\ Center, Post Box 96002300 RC \\ Leiden, The Netherlands \\ 2Department of Anesthesiology, \\ Leiden University Medical Center, \\ Leiden, The Netherlands \\ Full list of author information is \\ available at the end of the article
}

\begin{abstract}
Background: Mechanical ventilation and hyperoxia have the potential to independently promote lung injury and inflammation. Our purpose was to study both time- and dosedependent effects of supplemental oxygen in an experimental model of mechanically ventilated mice.

Methods: Healthy male C57BI/6J mice, aged 9-10 weeks, were intraperitoneally anesthetized and randomly assigned to the mechanically ventilated group or the control group. In total, 100 mice were tracheotomized and mechanically ventilated for either 8 or $12 \mathrm{~h}$ after allocation to different settings for the applied fractions of inspired oxygen $\left(\mathrm{FiO}_{2}\right.$, 30,50 , or $90 \%$ ) and tidal volumes (7.5 or $15 \mathrm{ml} / \mathrm{kg}$ ). After euthanisation arterial blood, bronchoalveolar lavage fluid (BALf) and tissues were collected for analyses.

Results: Mechanical ventilation significantly increased the lung injury score $(P<0.05)$, mean protein content $(P<0.001)$, and the mean number of cells $(P<0.01)$, including neutrophils in BALf $(P<0.001)$. In mice ventilated for $12 \mathrm{~h}$, a significant increase in TNF- $a$, IFN- $\gamma$, IL-1 $\beta, I L-10$, and MCP-1 $(P<0.01)$ was observed with $90 \% \mathrm{FiO}_{2}$, whereas IL-6 showed a decreasing trend ( $P$ for trend $=0.03$ ) across $\mathrm{FiO}_{2}$ groups. KC, MIP-2, and sRAGE were similar between $\mathrm{FiO}_{2}$ groups. HMGB-1 was significantly higher in BALf of mechanically ventilated mice compared to controls and showed a gradual increase in expression with increasing $\mathrm{FiO}_{2}$. Cytokine and chemokine levels in BALf did not markedly differ between $\mathrm{FiO}_{2}$ groups after $8 \mathrm{~h}$ of ventilation. Differences between the tidal volume groups were small and did not appear to significantly interact with the oxygen levels.

Conclusions: We demonstrated a severe vascular leakage and a pro-inflammatory pulmonary response in mechanically ventilated mice, which was enhanced by severe hyperoxia and longer duration of mechanical ventilation. Prolonged ventilation with high oxygen concentrations induced a time-dependent immune response characterized by elevated levels of neutrophils, cytokines, and chemokines in the pulmonary compartment.
\end{abstract}

Keywords: Hyperoxia, Mechanical ventilation, mice, VILI, Inflammation, Oxygen toxicity 


\section{Background}

Supplemental oxygen administration is essential to enhance survival in respiratory impaired and mechanically ventilated patients. Inspiratory fractions of oxygen $\left(\mathrm{FiO}_{2}\right)$ typically exceed concentrations of atmospheric air and are frequently applied for prolonged periods during mechanical ventilation in patients suffering from severe respiratory distress. However, both mechanical ventilation and hyperoxia can promote lung injury and induce adverse effects through diverse mechanisms. Clinical studies have retrospectively shown associations between arterial hyperoxia and poor outcomes during specific cardiovascular, neurological, respiratory, and traumatic events [1-4]. Accumulating evidence indicates a U-shaped survival curve of critically ill and mechanically ventilated patients in relation to arterial oxygen levels in the first $24 \mathrm{~h}$ of admission [5-8].

Impaired lung function may be caused by the adverse hemodynamic effects that are mainly imputed to direct vasoconstrictive actions of high oxygen concentrations, and atelectasis which may be aggravated by local and systemic inflammatory responses. These responses have repeatedly been documented in rodents following hyperoxic exposure in inhalation chambers [9-15]. Although hyperoxia has been suggested to induce time-dependent inflammatory responses [10], studies in animals are usually restricted to periods of up to $6 \mathrm{~h}$ of mechanical ventilation, limiting its clinical applicability [16-19]. Furthermore, the interaction between mechanical ventilation and concurrent hyperoxia may transcend lung injury by alveolar distention alone [9, 17, 20-22]. Given that oxygen therapy cannot altogether be avoided, we aimed to increase knowledge on the host response to different levels of oxygen. Hypothesizing that hyperoxia induces a dose-dependent gradual inflammatory response that may be aggravated by prolonged periods of mechanical ventilation, our purpose was to induce hyperoxia in mice and study both time- and dose-dependent inflammation effects of supplemental oxygen during prolonged ventilatory support with protective and injurious tidal volumes.

\section{Methods}

The Animal Care and Use Committee of the Academic Medical Center of the University of Amsterdam, The Netherlands, approved the study protocol in accordance with applicable research and ethical protocols. Animal procedures were performed in consistence with Institutional Standards for Care and Use of Laboratory Animals.

\section{Animals}

Healthy male C57Bl/6J mice were obtained from Charles River (Maastricht, The Netherlands) and housed in a temperature- and light-controlled room. The animals were acclimatized at the animal facility for at least 7 days and had free access to rodent chow and water. Animal welfare was warranted throughout the experiment [23]. Conscious animals were injected twice for intraperitoneal prehydration and anesthesia induction. Thereafter, mice were regularly checked on pain stimuli and discomfort. The titration scheme for adequate anesthesia was determined in pilot experiments. 
Design

At baseline, 109 mice aged 9-10 weeks (20-28 g) were intraperitoneally prehydrated with a bolus of $1 \mathrm{ml}$ normal saline and randomly assigned to the mechanical ventilation $(\mathrm{MV})$ group $(n=100)$ or the control group $(n=9)$. All mice in the MV group were randomized to subgroups ( $n=8-9$ per subgroup) by allocating different settings for the applied fractions of inspired oxygen $\left(\mathrm{FiO}_{2}=30,50\right.$, or $\left.90 \%\right)$, tidal volume (TV=7.5 or $15 \mathrm{ml} / \mathrm{kg}$ ), and MV duration (8 or $12 \mathrm{~h}$ ). The control group mice were spread over multiple days along with the instrumentation of the MV groups during the whole experimental period.

Experimental procedures have been described in detail previously [24, 25]. One hour after prehydration, mice assigned to the MV groups ( $n=8-9$ per group) were anesthetized with a $0.15-0.21 \mathrm{ml}$ intraperitoneal bolus of $126 \mathrm{mg} / \mathrm{kg}$ ketamine (Eurovet Animal Health BV, Bladel, The Netherlands), $0.1 \mathrm{mg} / \mathrm{kg}$ dexmedetomidine $0.5 \mathrm{mg} / \mathrm{ml}$ (Elanca Animal Health, Houten, The Netherlands), $0.5 \mathrm{mg} / \mathrm{kg}$ atropine sulfate (Centrafarm BV, Etten-Leur, The Netherlands), and $5 \mathrm{ml} / \mathrm{kg} 0.9 \%$ saline. Maintenance anesthesia was injected hourly through an intraperitoneal catheter (PE 10 tubing, BD, Breda, The Netherlands) and consisted of $36 \mathrm{mg} / \mathrm{kg}$ ketamine, $0.02 \mathrm{mg} / \mathrm{kg}$ dexmedetomidine, $0.075 \mathrm{mg} / \mathrm{kg}$ atropine sulfate, and $9.45 \mathrm{ml} / \mathrm{kg} 0.65 \%$ saline. A $1: 5 \mathrm{mix}$ of $0.65 \%$ saline and $8.4 \%$ sodium bicarbonate was intraperitoneally administered through the catheter every $30 \mathrm{~min}$ in order to compensate for fluid loss and maintain physiological bicarbonate levels [25]. Body temperature was strictly controlled between 36.5 and $37.5{ }^{\circ} \mathrm{C}$. Systolic blood pressure and heart rate were noninvasively measured using a murine tail pressure cuff with pulse transducer and monitored on a data acquisition system (LabChart, ADInstruments Ltd, Oxford, UK). Tidal volumes were monitored using a calibrated pneumotachometer (tracheal cannula $\mathrm{OD}=1.3 \mathrm{~mm}$, PTM type 378/0.9, HSE-Harvard Apparatus $\mathrm{GmbH}$, March-Hugstetten, Germany) and respiration data acquisition software (BDAS, HSE-Harvard Apparatus GmbH).

Anesthetized mice were tracheotomized, and a Y-tube connector (OD $1.0 \mathrm{~mm}$, ID $0.6 \mathrm{~mm}$ ) was surgically inserted in the trachea and fixed above the carina. Subsequently, animals were placed on a heating plate in supine position and connected to the ventilator (Babylog 8000 plus, Dräger Medical, Lübeck, Germany). Ventilator settings were pre-determined in pilot experiments and targeted at normal acid-base balance [24]. Ventilators were pressure-controlled and set to deliver low tidal volume (LTV, $7.5 \mathrm{ml} / \mathrm{kg}$ ) or high tidal volume (HTV, $15 \mathrm{ml} / \mathrm{kg})$. In both ventilation strategies, positive end-expiratory pressure (PEEP) levels were set at $3 \mathrm{cmH}_{2} \mathrm{O}$ and the inspiration to expiration ratio at 1:2.8. Respiratory rates were controlled at 160 (LTV) or 52 (HTV) breaths per minute. Recruitment maneuvers were performed every 30 (LTV) or 60 (HTV) minutes by means of inspiratory holds with a pressure of 20 mbar during $5 \mathrm{~s}$.

Immediately after randomization, ventilators were adjusted to the assigned settings by an independent biotechnician. Inspiratory pressures were adjusted and regulated to achieve appropriate TV throughout the experiment. At the end of the experiment, ventilated mice were euthanized by withdrawing blood from the carotid artery. Researchers were blinded for administered $\mathrm{FiO}_{2}$ levels during the experimental procedures. The allocation code of randomization was supplied by the time all data and assay results were collected. 


\section{Measurements}

After euthanization, arterial blood was collected in heparin-coated syringes and used for blood gas analysis (Rapidpoint 405, Siemens Healthcare, Tarrytown, NY, USA). Lungs were resected en bloc, and the right lung was instilled with normal saline $(3 \times 0.5 \mathrm{ml})$ to obtain bronchoalveolar lavage fluid (BALf), which was used for automated cell counting (Z2 Beckman Coulter Counter, Brea, USA). Differential counts were performed on Giemsa stained cytospin slides. BALf was centrifuged, and the supernatant was stored at $-80{ }^{\circ} \mathrm{C}$ for assessment of protein levels and cytokines. The left lung was weighed and thereafter fixed in $4 \%$ formalin and embedded in paraffin. Lung sections were stained with hematoxylin eosin (H\&E) to analyze lung histopathology. A dedicated pathologist determined the histopathological lung injury score on a nominal scale by the sum of the score for four pathologic parameters: edema, hemorrhage, interstititial cell infiltration, and hyaline membranes as described previously [24]. Relative lung weight, expressed as lung weight corrected for total body weight at baseline, was used as surrogate for lung tissue edema.

Cytokines (IL-1 $\beta$, IL-6, IL-10, MCP-1, MIP-2, KC, TNF- $\alpha$, IFN- $\gamma$ ) were measured in BALf by Luminex (Merck Millipore Chemicals BV, Amsterdam, The Netherlands). High-mobility group box-1 (HMGB-1, IBL International BV, Amersfoort, The Netherlands) and the soluble receptor for advanced glycation end products (sRAGE, R\&D Systems, Abingdon, UK) were determined by enzymelinked immunosorbent assays (ELISA) according to the manufacturer's protocols. Total protein levels were determined in serum and BALf (Oz Biosciences, Marseille, France), using bovine serum albumin as reference.

The right lung was used for total RNA isolation from tissue homogenates (RNABee, Tel-Test Inc, Bio-Connect BV, Huissen, The Netherlands), first-strand cDNA synthesis (SuperScript Choice System, Life Technologies, Breda, The Netherlands), and real-time quantitative PCR (TNF- $\alpha$, IL-6, MMP-12, MCP-1, TF, PAI-1), using $\beta$-actin as a housekeeping gene reference, were performed on a LightCycler 480 (Roche, Almere, The Netherlands) of the Leiden Genome Technology Center (Leiden, The Netherlands) as described previously [26].

\section{Statistical analysis}

The partial pressure of arterial oxygen $\left(\mathrm{PaO}_{2}\right)$ at the end of the experiment was defined as the primary outcome. Inflammatory markers and markers of lung injury were assessed as secondary outcomes. Based on previous pilot results and with a group size of eight animals per group the Wilcoxon rank-sum test ensures $80 \%$ power using a two-sided significance level of 0.05 to detect an estimated effect size of 1.85 that the observed parameter differs between groups. With an anticipated dropout rate of one per group, nine animals were initially assigned to each group. Differences between study groups were tested with one-way analysis of variance or Kruskal Wallis as appropriate. Cuzick's test was used to test for trends across different $\mathrm{FiO}_{2}$ groups. Statistical analyses were performed using $\mathrm{R}$ version 3.2 .1 ( $\mathrm{R}$ Foundation for Statistical Computing, Vienna, Austria) and STATA/SE 10.1 (StataCorp LP, College Station, TX, USA). 


\section{Results}

All mice survived mechanical ventilation with the applied settings in a volumetargeted approach (Table 1). Mean systolic blood pressures decreased gradually during 8 or $12 \mathrm{~h}$ of mechanical ventilation (145 to $90 \mathrm{mmHg}$ ) and were slightly higher in the $90 \% \mathrm{FiO}_{2}$ group (Table 1, Additional file 1 Figure S1). Heart rates and body temperatures remained stable throughout the experiment.

Data are means $\pm \mathrm{SD}$. $\mathrm{TV}=$ tidal volume, $\mathrm{P}_{\text {insp }}=$ inspiratory pressure, $\mathrm{SBP}=$ systolic blood pressure. All indicated parameters were measured hourly.

\section{Oxygenation and ventilation}

The partial pressure of oxygen in the carotid arterial blood at the end of mechanical ventilation was distinctly higher with increasing fractions of supplied oxygen $\left(P<0.001\right.$, Fig. 1a). Partial pressure of arterial carbon dioxide $\left(\mathrm{PaCO}_{2}\right)$ was in general lower for the HTV groups but did not show a trend across $\mathrm{FiO}_{2}$ groups (Fig. 1b). The $\mathrm{PaO}_{2} / \mathrm{FiO}_{2}$ ratio decreased for mechanically ventilated mice in comparison to controls and was markedly higher for HTV groups after $12 \mathrm{~h}$ of mechanical ventilation (Fig. 1c). Dynamic lung compliance decreased gradually over the study interval for all study groups, but the decrease was nearly complete after $3 \mathrm{~h}$ of mechanical ventilation and was larger for the HTV groups (Fig. 1d).

\section{Markers of lung injury}

Mechanical ventilation significantly increased the lung injury score (Fig. 2a, 1.6-fold at $8 \mathrm{~h}, P<0.01$; and 1.5 -fold at $12 \mathrm{~h}, P<0.05$ ), mean protein content (Fig. $2 \mathrm{~b}$, 2.6-fold at $8 \mathrm{~h}, P<0.001$; and 2.2-fold at $12 \mathrm{~h}, P<0.001$ ), and the mean number of cells (Fig. 2c, 1.7-fold at $8 \mathrm{~h}, P<0.01$; and 2.0-fold at $12 \mathrm{~h}, P<0.001$ ), including neutrophils in BALf (Fig. 2d, 132-fold at $8 \mathrm{~h}, P<0.001$; and 180-fold at $12 \mathrm{~h}, P<0.001$ ), demonstrating vascular leakage and inflammation as a result of mechanical ventilation even at relatively low hyperoxic conditions of $30 \% \mathrm{FiO}_{2}$ and low tidal volumes. Increased hyperoxia up to $90 \% \mathrm{FiO}_{2}$ did not further increase protein content or the total number of cells in BALf but showed an increased trend in the percentage of neutrophils towards higher $\mathrm{FiO}_{2}$ levels $(P$ for trend $=0.03)$. Histopathology showed a decrease in air restraint, suggesting progressive alveolar collapse, with higher

Table 1 Ventilation and hemodynamic parameters

\begin{tabular}{|c|c|c|c|c|c|c|}
\hline & $8 \mathrm{~h}$ & & & $12 \mathrm{~h}$ & & \\
\hline & $30 \%$ & $50 \%$ & $90 \%$ & $30 \%$ & $50 \%$ & $90 \%$ \\
\hline LTV & & & & & & \\
\hline $\mathrm{TV}(\mu \mathrm{l})$ & $181(0)$ & $182(0)$ & $179(0)$ & $176(0)$ & $178(1)$ & $176(0)$ \\
\hline$P_{\text {insp }}(m b a r)$ & $13(0)$ & $14(0)$ & $12(0)$ & $12(0)$ & $13(0)$ & $12(0)$ \\
\hline $\mathrm{SBP}(\mathrm{mmHg})$ & $116(7)$ & $128(7)$ & $123(5)$ & $103(4)$ & $102(5)$ & $112(4)$ \\
\hline HTV & & & & & & \\
\hline TV $(\mu \mathrm{l})$ & $351(0)$ & $379(1)$ & $372(1)$ & $366(2)$ & $371(1)$ & $360(1)$ \\
\hline$P_{\text {insp }}$ (mbar) & $20(0)$ & $21(0)$ & $20(0)$ & $20(0)$ & $20(0)$ & $20(0)$ \\
\hline $\mathrm{SBP}(\mathrm{mmHg})$ & $114(6)$ & $136(8)$ & $124(7)$ & $104(4)$ & $110(6)$ & $113(5)$ \\
\hline
\end{tabular}




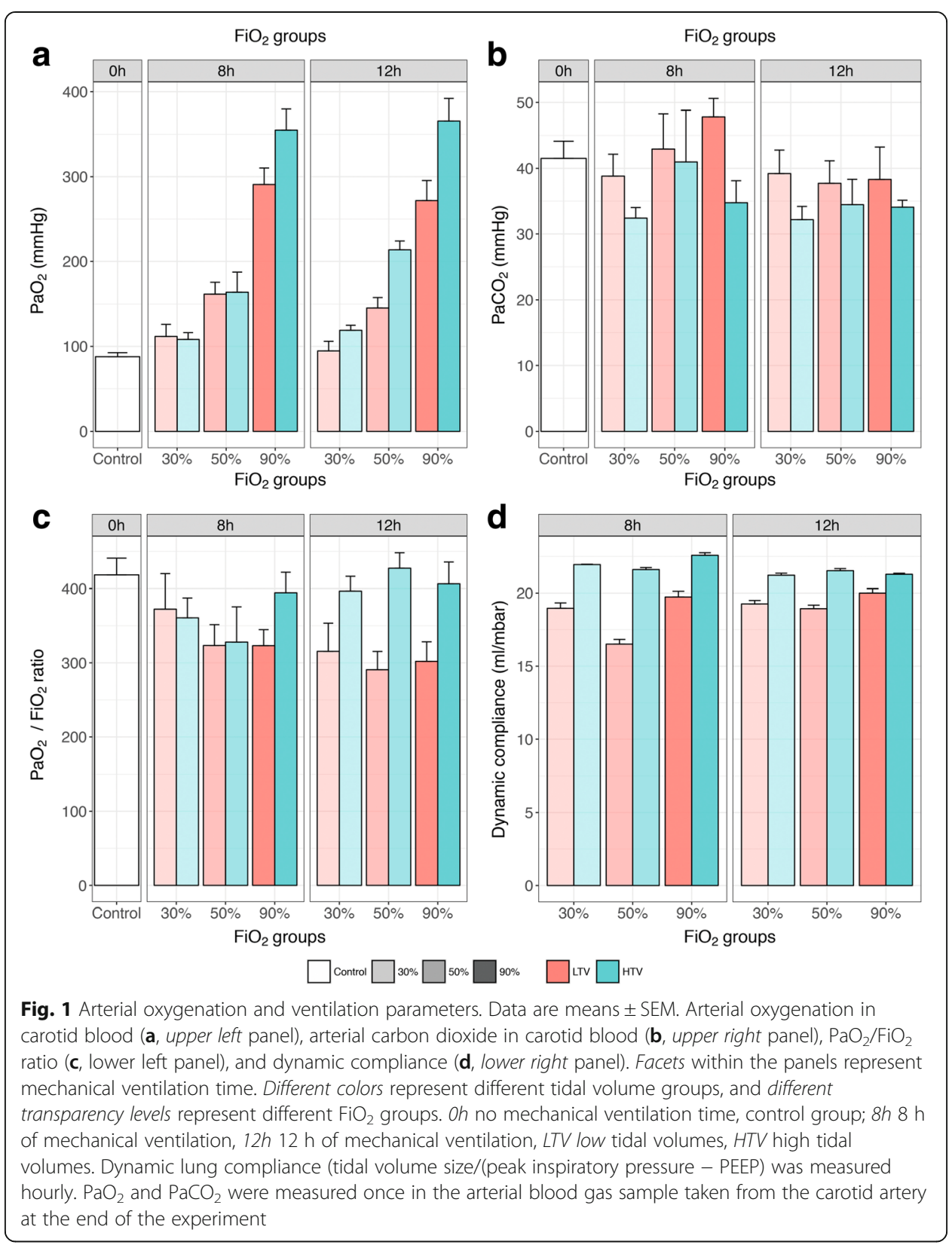

oxygen levels (Additional file 1 Figure S2), but this was not translated in a significant difference in the lung injury score between the different $\mathrm{FiO}_{2}$ groups (Fig. 2a).

\section{Markers of inflammation}

Cytokine and chemokine levels in BALf increased at 8 and $12 \mathrm{~h}$ after mechanical ventilation but did not markedly differ between $\mathrm{FiO}_{2}$ groups at $8 \mathrm{~h}$ of ventilation $(P$ for trend $>0.05$, Additional file 1 Figure S3). In mice ventilated for $12 \mathrm{~h}$, a significantly increasing trend in TNF- $\alpha$, IFN- $\gamma$, IL-1 $\beta$, IL-10, and MCP-1 (Fig. 3, $P$ for trend $<0.01$ ) was observed with increasing $\mathrm{FiO}_{2}$, whereas IL- 6 showed a decreasing trend $(P$ for trend $=0.03)$. KC, MIP-2, and sRAGE were similar between $\mathrm{FiO}_{2}$ 

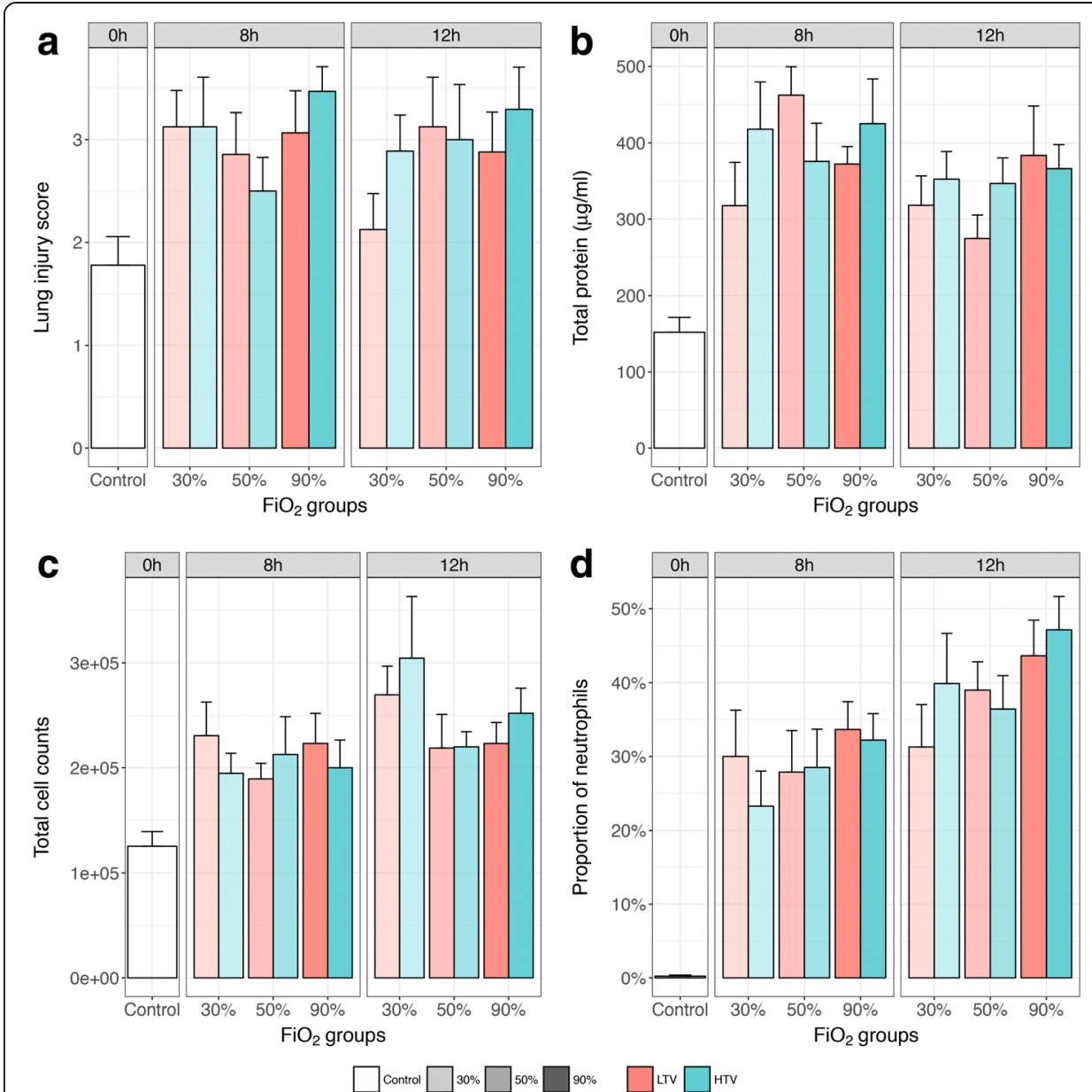

Fig. 2 Markers of lung injury in BALf after indicated study interval. Data are means \pm SEM. Lung injury score (a, upper left panel), total protein content (b, upper right panel), total cell counts (c, lower left panel), and proportion of neutrophils (d, lower right panel) in BALf obtained after the study interval. Facets within the panels represent mechanical ventilation time. Different colors represent different tidal volume groups, and different transparency levels represent different $\mathrm{FiO}_{2}$ groups. Oh no mechanical ventilation time, control group; $8 \mathrm{~h} 8 \mathrm{~h}$ of mechanical ventilation, $12 \mathrm{~h} 12 \mathrm{~h}$ of mechanical ventilation, LTV low tidal volumes, HTV high tidal volumes

groups. HMGB-1 was significantly higher in BALf of mechanically ventilated mice compared to controls and showed a gradual increase in expression with increasing $\mathrm{FiO}_{2}$. Almost no differences in cytokine and chemokine levels in the BALf were observed between the 30 and $50 \%$ oxygen groups.

Differences between the tidal volume groups were small (Additional file 1 Figure S4) and did not appear to significantly interact with the oxygen levels $(P>0.50$ for the interaction term for each inflammatory mediator, except for IL-6, $P=0.03$ ). Inflammatory markers were also measured at $12 \mathrm{~h}$ of mechanical ventilation in the serum and are shown in Additional file 1 Figure S5.

The RNA expression of selected markers showed an increased relative expression of TNF- $\alpha$, IL- 6 , and MCP-1 in lung homogenate of mice that were mechanically ventilated with high tidal volumes compared to controls (Additional file 1 Figure 6). 

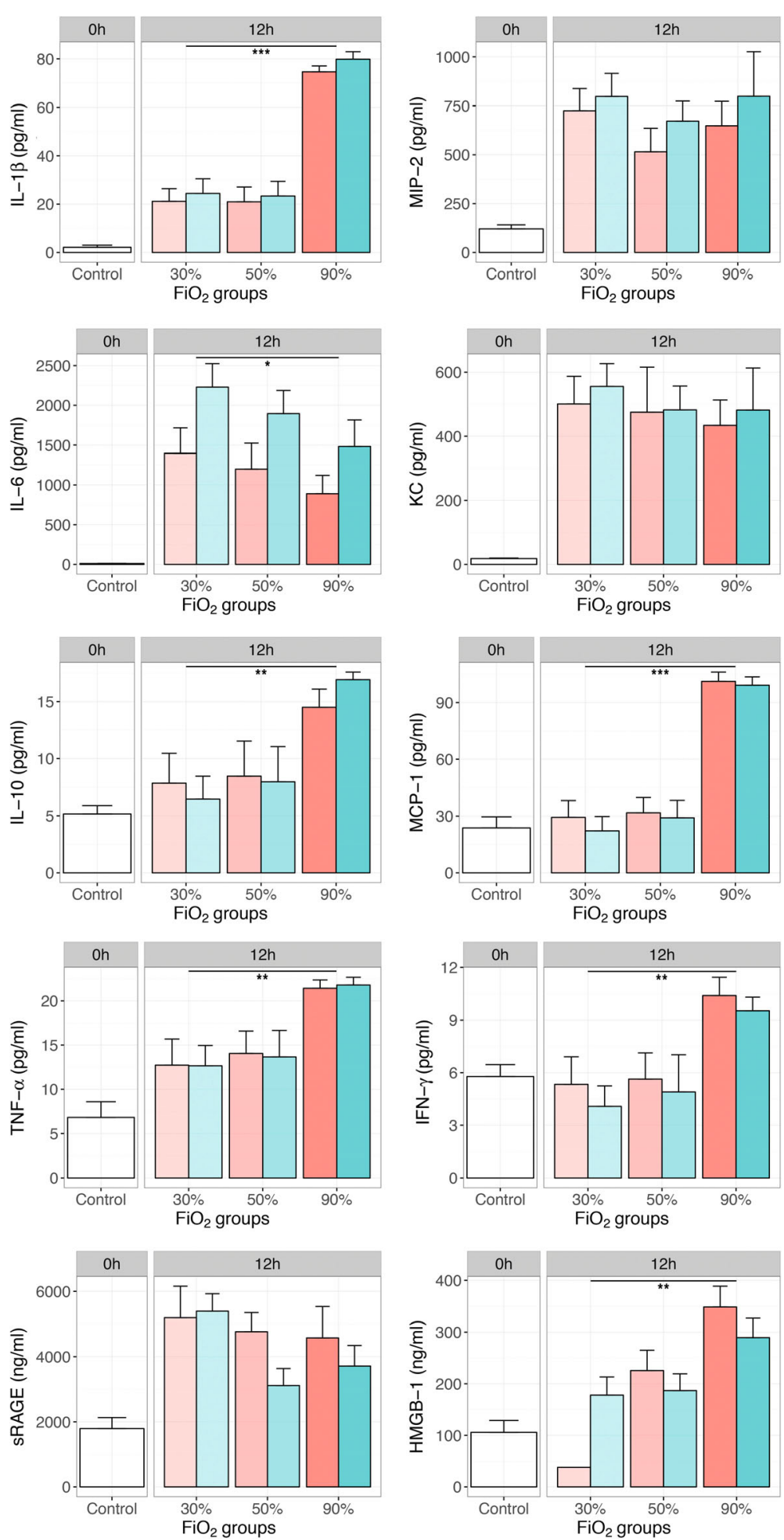

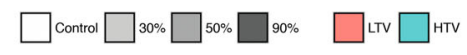

Fig. 3 (See legend on next page.) 
(See figure on previous page.)

Fig. 3 Inflammatory mediators in BALf in controls and after $12 \mathrm{~h}$ of mechanical ventilation. Cytokine and chemokine levels in BALf obtained after $12 \mathrm{~h}$ of mechanical ventilation. Data are means \pm SEM. Facets within the panels represent mechanical ventilation time. Different colors represent different tidal volume groups, and different transparency levels represent different $\mathrm{FiO}_{2}$ groups. Oh no mechanical ventilation time, control group; $12 \mathrm{~h} 12 \mathrm{~h}$ of mechanical ventilation, LTV low tidal volumes, HTV high tidal volumes. Cuzick's $P$ for trend in increasing oxygen levels at $12 \mathrm{~h}$ of mechanical ventilation: IL-1 $\beta,<0.001$; MIP-2, 0.27; IL-6, 0.03; KC, 0.22; IL-10, 0.001; MCP-1, <0.001; TNF-a, 0.001; IFN- $\gamma, 0.001$; sRAGE, 0.11; HMGB-1, 0.001. *P for trend $<0.05$; ${ }^{*} P$ for trend $<0.01$; ${ }^{* *} P$ for trend $<0.001$

\section{Discussion}

In this experimental study, we demonstrated a severe vascular leakage and a proinflammatory pulmonary response in mechanically ventilated mice, which was enhanced by severe hyperoxia and longer duration of mechanical ventilation. Prolonged ventilation with high oxygen concentrations induced a time-dependent immune response characterized by elevated levels of neutrophils, cytokines, and chemokines in the pulmonary compartment.

Although most studies in mechanically ventilated animals are restricted to short exposure periods, recent experiments in mechanically ventilated rodents, rabbits, and pigs, mimicking the clinical environment of critically ill patients, showed that hyperoxia serves as an important cofactor in acute lung injury, bacterial dissemination, progression of multiple system organ dysfunction, and lethality [13-15] but can also improve organ function and attenuate tissue apoptosis during shock [27]. In our study, divergent effects were observed in the expression of selected inflammatory markers across the experimental groups, which may be explained by the complex kinetics and dynamics of the immune response due to the concurrent exposure to anesthesia, mechanical ventilation, and hyperoxia. Interaction between pro- and anti-inflammatory cytokines may contribute to the differences in cytokine levels in the experimental groups. Rapid upregulation of TNF- $\alpha$ was seen even in the acute phase reaction after induction of anesthesia in control mice. Cytokine concentrations may decrease after long-term hyperoxic exposure, and a fast upregulation of inflammatory action can be followed by a gradual impairment or suppression of the innate immune system [28], which may in turn make the lung more susceptible to injury and infection. Differences in cytokine levels between the $\mathrm{FiO}_{2}$ groups were relatively mild. We observed a strong inflammatory effect at very high oxygen concentrations $\left(\mathrm{FiO}_{2} 90 \%\right)$ while the increase from 30 to $50 \%$ did not make a large difference. Indeed, $50 \%$ of inspired oxygen may not be as detrimental as $90 \%$ as evidenced by the clear increase in neutrophils and most cytokines during 90\% oxygen administration, which was also described in other studies [29-32]. In addition, ventilation with $30 \%$ may actually be a model of relative tissue hypoxia in mice following progressive lung injury during the experiment, although this was not reflected by the $\mathrm{PaO}_{2}$ levels. Comparison with control groups suggests that mechanical ventilation itself was very harmful, possibly not allowing additional damage by increasing oxidative stress. Both hypoxia and hyperoxia may induce oxidative stress, and relative changes in hyperoxia may trigger upregulation of the hypoxia inducible factor (HIF) [33].

Furthermore, damage-associated molecular pattern (DAMP) molecules play a key role in the inflammatory response to injury and have been suggested to modulate the effects of hyperoxia and oxidative stress $[34,35]$. In this matter, HMGB-1 has 
been described as the archetypal chemokine that is upregulated by the innate immune system in response to cell stress [36]. We also observed increased levels of this protein in the lungs of mechanically ventilated mice, particularly after concurrent exposure to high $\mathrm{FiO}_{2}$. The overall protein content did not significantly increase with severe hyperoxia, but this interpretation may be limited as we did not correct the protein in BALf for urea (epithelial lining fluid). The expression of most cytokines in BALf was not essentially different than in the serum, which may be a result of extended duration of mechanical ventilation causing systemic inflammation. In line with previous experiments, the presence of cytokines with short term ventilation was definitely more pronounced in the pulmonary compartment compared to circulating blood of rodents [25, 37].

Our study and others generated conflicting data regarding the inflammatory response after hyperoxic ventilation describing both pro- $[15,17,38,39]$ and anti-inflammatory $[40,41]$ responses. Kiers et al. recently demonstrated that, in the absence of systemic inflammation, short-term hyperoxia without mechanical ventilation does not result in increased levels of inflammatory cytokines, neutrophil phagocytosis, nor ROS generation in both mice and healthy volunteers [42]. In the present study, the expression of inflammatory markers was shown to be divergent after mechanical ventilation and with increasing $\mathrm{FiO}_{2}$, which is consistent with previous research [16]. Bailey et al. concluded that prolonged mechanical ventilation of healthy rat lungs with a physiological strategy can contribute to the inflammatory response and cause alterations to pulmonary surfactant [43]. Lung injury due to continuous hyperoxic exposure has also been shown to be dose-dependent in rats $[12,15]$.

Some clinical scenarios may dictate non-protective ventilation, both with high pressures and high levels of inspired oxygen in patients with heavily injured lungs. However, it is not exactly known whether this combination works synergistically in causing lung injury. Our data do not imply such an "add-on effect," but the discrepancy with a previous study [20] may be explained by the use of lower tidal volumes in our study. It is also possible that the extended duration of mechanical ventilation alone was enough to cause ventilator-induced lung injury (VILI) without an additional effect of tidal volume size. An alternative explanation may be that lower respiratory rates compensated for high tidal volumes, while higher respiratory rates increased the risk of lung injury in the lower tidal volume groups. Also, some of the deleterious properties of hyperoxia may be overcome by applying PEEP, as it may counteract alveolar collapse from progressive nitrogen washout and mitigate the effects of atelectrauma [44].

In our study, lung injury scores did not reveal any histopathological difference between study groups. However, in previous work using a high tidal volume strategy with zero PEEP, total histopathology scores were shown to be higher compared to low tidal volumes and $3 \mathrm{cmH}_{2} \mathrm{O}$ PEEP with a marginal additive effect of ventilation duration [24]. This was in accordance with a study reporting that pre-exposure to hyperoxia increases the susceptibility to VILI before initiation of mechanical ventilation [22]. Others documented that short-term exposure to levels of oxygen up to $100 \%$ does not increase the changes in respiratory system mechanics induced by mechanical ventilation [16]. The progressive airway collapse and inflammation with increasing $\mathrm{FiO}_{2}$ may not have been severe enough to induce histopathological changes and affect lung function in our model. The striking heterogeneity that exists between experimental studies may be 
explained by differences in subjects (e.g., species, strains, genetical modification, age, sex), and exposure (e.g., pre-exposure, severity, duration, anesthesia, ventilation).

Although the experiments were performed according to the high standards for methodological quality of animal research [45], several limitations may apply to our experimental procedures. The lavage technique of the lungs may induce subtle differences in the dilution of returned fluid, although saline injection volumes were standardized. Storage of biological specimens was secured according to high-quality protocols. Our analyses were restricted to specific features of injurious ventilation and hyperoxia, yet other underlying mechanisms affecting reactive oxygen species and mitochondrial damage have not been considered. Other covariates such as $\mathrm{PaCO}_{2}$ may have influenced the results, even though this cannot be seen separate from ventilation settings and was inherent to adjusting tidal volumes and $\mathrm{FiO}_{2}$. Furthermore, low respiratory rates, especially in the LTV group, are subphysiological for mice and may cause relative hypercapnia.

The experimental setting may hamper translation of study results to the clinical setting. Indeed, smaller species, such as mice have different lung mechanics and immune reactions than humans [46, 47]. Healthy mice may also respond differently than critically ill patients, especially in case of injured lungs prior to the start of mechanical ventilation. Interestingly, moderate hyperoxia in mechanically ventilated patients without severe respiratory failure does not appear to increase systemic or pulmonary inflammation [48].

Further, the $\mathrm{C} 57 \mathrm{Bl} / 6 \mathrm{~J}$ type mice that we used are the most widely used strain of mice for experimental research but have been shown to carry a spontaneous mutation, which can result in mitochondrial redox abnormalities and may influence the functionality of the hyperoxia defense [49].

Strengths of this study include the prolonged duration of mechanical ventilation which may be representative of the intensive care unit (ICU) setting, where hyperoxia acts as a second hit on top of VILI. Indeed, we showed that the immune response was considerably stronger at $12 \mathrm{~h}$ of mechanical ventilation compared to $8 \mathrm{~h}$, which may imply that models applying mechanical ventilation for extended duration more accurately reflect the underlying mechanisms and long-term effects. Demonstrable lung injury may follow the inflammatory response even later than after $12 \mathrm{~h}$ of hyperoxic mechanical ventilation. As such, our results further accentuate that we should limit the exposure to supraphysiological oxygen levels from excessive oxygen supply when prolonged periods of mechanical ventilation are anticipated.

\section{Conclusions}

Prolonged experimental hyperoxic mechanical ventilation was associated with a significant inflammatory response in the lung as evidenced by an influx of neutrophils in the pulmonary compartment and upregulation of specific inflammatory markers, which was not directly translated into extensive tissue lung injury or a change in lung compliance. The present experimental data may aid to determine optimal ventilator strategies in mechanically ventilated patients, but the dynamics and kinetics of hyperoxic ventilation need further exploration in order to characterize the long-term effects and investigate protective measures. 


\section{Additional files}

Additional file 1: Figure S1. Mean systolic blood pressure over the study interval. Figure S2. Microscopic histopathology of representative mouse lung sections after $12 \mathrm{~h}$ of mechanical ventilation (H\&E staining, $\times 10$ magnification). Figure S3. Inflammatory mediators in BALf after 8 h of mechanical ventilation. Figure S4. Inflammatory mediators in BALf after study interval by tidal volume size. Figure S5. Inflammatory mediators in serum after $12 \mathrm{~h}$ of mechanical ventilation. Figure S6. Relative RNA expression of inflammatory markers in lung homogenate after $12 \mathrm{~h}$ of mice that were mechanically ventilated with high tidal volumes compared to controls.

\section{Abbreviations}

BALf: Bronchoalveolar lavage fluid; DAMP: Damage associated molecular pattern; ELISA: Enzyme-linked immunosorbent assays; $\mathrm{FiO}_{2}$ : Fraction of inspired oxygen; HIF: Hypoxia inducible factor; HMGB-1: High-mobility group box-1; HTV: High

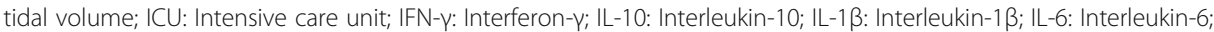
KC: Kupffer Cell; LTV: Low tidal volume; MCP-1: Monocyte Chemoattractant Protein-1; MIP-2: Macrophage Inflammatory Protein-2; MV: Mechanical ventilation; $\mathrm{PaCO}_{2}$ : Partial pressure of arterial carbon dioxide; $\mathrm{PaO}_{2}$ : Partial pressure of arterial oxygen; PEEP: Positive end-expiratory pressure; sRAGE: soluble Receptor for Advanced Glycation End products; TNF-a: Tumor necrosis factor-a; TV: Tidal volume; VILI: Ventilator-induced lung injury

\section{Acknowledgements}

Biotechnical and bio-analytical assistance by Jacoline Buchner-Doeven and Anita Tuip-de Boer is gratefully acknowledged.

\section{Funding}

Hendrik J.F. Helmerhorst is supported by the ESICM Young Investigator Award.

\section{Availability of data and materials}

All data are presented within the manuscript or in the additional files.

\section{Authors' contributions}

$\mathrm{HH}$ had full access to the data in the study and takes responsibility for the integrity of the data and the accuracy of the data analysis. LS assisted in the execution of the experimental procedures and contributed to the critical revision of the manuscript. GW assisted in analysis and interpretation of the RNA data from tissue homogenate and contributed to the critical revision of the manuscript. JR assisted in the analysis and interpretation of lung histopathology and contributed to the critical revision of the manuscript. HH, NJ, MS, EdJ, and DvW contributed substantially to the study design, interpretation of the data, and writing and critical revision of the manuscript. All authors read and approved the final manuscript.

\section{Competing interests}

The authors declare that they have no competing interests.

\section{Consent for publication}

Not applicable.

\section{Ethics approval}

The Animal Care and Use Committee of the Academic Medical Center of the University of Amsterdam, The Netherlands, approved the study protocol in accordance with applicable research and ethical protocols. Animal procedures were performed in consistence with Institutional Standards for Care and Use of Laboratory Animals.

\section{Publisher's Note}

Springer Nature remains neutral with regard to jurisdictional claims in published maps and institutional affiliations.

\section{Author details}

${ }^{1}$ Department of Intensive Care Medicine, Leiden University Medical Center, Post Box 96002300 RC Leiden, The Netherlands. ${ }^{2}$ Department of Anesthesiology, Leiden University Medical Center, Leiden, The Netherlands. ${ }^{3}$ Laboratory of Experimental Intensive Care and Anesthesiology, Academic Medical Center, Amsterdam, The Netherlands. ${ }^{4}$ Department of Intensive Care Medicine, Academic Medical Center, Amsterdam, The Netherlands. ${ }^{5}$ Department of Pediatrics, Laboratory of Neonatology, University Medical Center Leiden, Leiden, The Netherlands. ${ }^{6}$ Department of Pathology, Academic Medical Center, Amsterdam, The Netherlands.

Received: 27 January 2017 Accepted: 18 May 2017

Published online: 26 May 2017

\section{References}

1. Austin MA, Wills KE, Blizzard L, Walters EH, Wood-Baker R (2010) Effect of high flow oxygen on mortality in chronic obstructive pulmonary disease patients in prehospital setting: randomised controlled trial. BMJ 341:c5462

2. Farquhar $H$, Weatherall M, Wijesinghe M, Perrin K, Ranchord A, Simmonds M, Beasley R (2009) Systematic review of studies of the effect of hyperoxia on coronary blood flow. Am Heart J 158(3):371-377

3. Kilgannon JH, Jones AE, Shapiro NI, Angelos MG, Milcarek B, Hunter K, Parrillo JE, Trzeciak S, EMSRN E (2010) Association between arterial hyperoxia following resuscitation from cardiac arrest and in-hospital mortality. JAMA 303(21):2165-2171 
4. Helmerhorst HJ, Roos-Blom MJ, van Westerloo DJ, de Jonge E (2015) Association between arterial hyperoxia and outcome in subsets of critical illness: a systematic review, meta-analysis, and meta-regression of cohort studies. Crit Care Med 43(7):1508-1519

5. de Jonge E, Peelen L, Keijzers PJ, Joore H, de Lange D, van der Voort PH, Bosman RJ, de Waal RA, Wesselink R, de Keizer NF (2008) Association between administered oxygen, arterial partial oxygen pressure and mortality in mechanically ventilated intensive care unit patients. Crit Care 12(6):R156

6. Eastwood G, Bellomo R, Bailey M, Taori G, Pilcher D, Young P, Beasley R (2012) Arterial oxygen tension and mortality in mechanically ventilated patients. Intensive Care Med 38(1):91-98

7. Helmerhorst HJ, Roos-Blom MJ, van Westerloo DJ, Abu-Hanna A, de Keizer NF, de Jonge E (2015) Associations of arterial carbon dioxide and arterial oxygen concentrations with hospital mortality after resuscitation from cardiac arrest. Crit Care 19:348

8. Helmerhorst HJ, Arts DL, Schultz MJ, van der Voort PH, Abu-Hanna A, de Jonge E, van Westerloo DJ (2017) Metrics of arterial hyperoxia and associated outcomes in critical care. Crit Care Med 45(2):187-195

9. Bailey TC, Martin EL, Zhao L, Veldhuizen RA (2003) High oxygen concentrations predispose mouse lungs to the deleterious effects of high stretch ventilation. J Appl Physiol (1985) 94(3):975-982

10. Nagato AC, Bezerra FS, Lanzetti M, Lopes AA, Silva MA, Porto LC, Valenca SS (2012) Time course of inflammation, oxidative stress and tissue damage induced by hyperoxia in mouse lungs. Int J Exp Pathol 93(4):269-278

11. Martin EL, MCCaig LA, Moyer BZ, Pape MC, Leco KJ, Lewis JF, Veldhuizen RA (2005) Differential response of TIMP-3 null mice to the lung insults of sepsis, mechanical ventilation, and hyperoxia. Am J Physiol Lung Cell Mol Physiol 289(2):L244-251

12. Nagato A, Silva FL, Silva AR, Bezerra FS, Oliveira ML, Bello-Klein A, Cristovao Porto L, Santos Valenca S (2009) Hyperoxia-induced lung injury is dose dependent in Wistar rats. Exp Lung Res 35(8):713-728

13. Kikuchi Y, Tateda K, Fuse ET, Matsumoto T, Gotoh N, Fukushima J, Takizawa H, Nagase T, Standiford TJ, Yamaguchi K (2009) Hyperoxia exaggerates bacterial dissemination and lethality in Pseudomonas aeruginosa pneumonia. Pulm Pharmacol Ther 22(4):333-339

14. Tateda K, Deng JC, Moore TA, Newstead MW, Paine R 3rd, Kobayashi N, Yamaguchi K, Standiford TJ (2003) Hyperoxia mediates acute lung injury and increased lethality in murine Legionella pneumonia: the role of apoptosis. J Immunol 170(8):4209-4216

15. Rodriguez-Gonzalez R, Martin-Barrasa JL, Ramos-Nuez A, Canas-Pedrosa AM, Martinez-Saavedra MT, Garcia-Bello MA, Lopez-Aguilar J, Baluja A, Alvarez J, Slutsky AS et al (2014) Multiple system organ response induced by hyperoxia in a clinically relevant animal model of sepsis. Shock 42(2):148-153

16. Cannizzaro V, Berry LJ, Zosky GR, Turner DJ, Hantos Z, Sly PD (2009) Impact of supplemental oxygen in mechanically ventilated adult and infant mice. Respir Physiol Neurobiol 165(1):61-66

17. Li LF, Liao SK, Ko YS, Lee CH, Quinn DA (2007) Hyperoxia increases ventilator-induced lung injury via mitogenactivated protein kinases: a prospective, controlled animal experiment. Crit Care 11(1):R25

18. Andrade PV, Dos Santos JM, Silva HC, Wilbert DD, Cavassani SS, Oliveira-Junior IS (2013) Influence of hyperoxia and mechanical ventilation in lung inflammation and diaphragm function in aged versus adult rats. Inflammation 37(2):486-494

19. Cavassani SS, Junqueira VB, Moraes JB, Luzo KK, Silva CM, Barros M, Marinho M, Simoes RS, Oliveira-Junior IS (2011) Short courses of mechanical ventilation with high-O2 levels in elderly rat lungs. Acta Cir Bras 26(2):107-113

20. Sinclair SE, Altemeier WA, Matute-Bello G, Chi E (2004) Augmented lung injury due to interaction between hyperoxia and mechanical ventilation. Crit Care Med 32(12):2496-2501

21. Altemeier WA, Sinclair SE (2007) Hyperoxia in the intensive care unit: why more is not always better. Curr Opin Crit Care 13(1):73-78

22. Makena PS, Luellen CL, Balazs L, Ghosh MC, Parthasarathi K, Waters CM, Sinclair SE (2010) Preexposure to hyperoxia causes increased lung injury and epithelial apoptosis in mice ventilated with high tidal volumes. Am J Physiol Lung Cell Mol Physiol 299(5):L711-719

23. Huet O, de Haan JB (2014) The ethical dimension in published animal research in critical care: the dark side of our moon. Crit Care 18(1):120

24. Hegeman MA, Hemmes SN, Kuipers MT, Bos LD, Jongsma G, Roelofs JJ, van der Sluijs KF, Juffermans NP, Vroom MB, Schultz MJ (2013) The extent of ventilator-induced lung injury in mice partly depends on duration of mechanical ventilation. Crit Care Res Pract 2013:435236

25. Wolthuis EK, Vlaar AP, Choi G, Roelofs JJ, Juffermans NP, Schultz MJ (2009) Mechanical ventilation using non-injurious ventilation settings causes lung injury in the absence of pre-existing lung injury in healthy mice. Crit Care 13(1):R1

26. Wagenaar GT, ter Horst SA, van Gastelen MA, Leijser LM, Mauad T, van der Velden PA, de Heer E, Hiemstra PS, Poorthuis BJ, Walther FJ (2004) Gene expression profile and histopathology of experimental bronchopulmonary dysplasia induced by prolonged oxidative stress. Free Radic Biol Med 36(6):782-801

27. Barth E, Bassi G, Maybauer DM, Simon F, Groger M, Oter S, Speit G, Nguyen CD, Hasel C, Moller P et al (2008) Effects of ventilation with 100\% oxygen during early hyperdynamic porcine fecal peritonitis. Crit Care Med 36(2):495-503

28. Baleeiro CE, Wilcoxen SE, Morris SB, Standiford TJ, Paine R 3rd (2003) Sublethal hyperoxia impairs pulmonary innate immunity. J Immunol 171(2):955-963

29. Okuma T, Terasaki Y, Sakashita N, Kaikita K, Kobayashi H, Hayasaki T, Kuziel WA, Baba H, Takeya M (2006) MCP-1/CCR2 signalling pathway regulates hyperoxia-induced acute lung injury via nitric oxide production. Int J Exp Pathol 87(6):475-483

30. Chen CM (2015) Interluekin-10 for hyperoxia-induced acute lung injury: a new direction? Exp Physiol 100(3):229

31. Min JH, Codipilly CN, Nasim S, Miller EJ, Ahmed MN (2012) Synergistic protection against hyperoxia-induced lung injury by neutrophils blockade and EC-SOD overexpression. Respir Res 13:58

32. Yamada M, Kubo H, Kobayashi S, Ishizawa K, Sasaki H (2004) Interferon-gamma: a key contributor to hyperoxiainduced lung injury in mice. Am J Physiol Lung Cell Mol Physiol 287(5):L1042-1047

33. Asikainen TM, Schneider BK, Waleh NS, Clyman RI, Ho WB, Flippin LA, Gunzler V, White CW (2005) Activation of hypoxia-inducible factors in hyperoxia through prolyl 4-hydroxylase blockade in cells and explants of primate lung. Proc Natl Acad Sci U S A 102(29):10212-10217 
34. Helmerhorst HJ, Schultz MJ, van der Voort PH, de Jonge E, van Westerloo DJ (2015) Bench-to-bedside review: the effects of hyperoxia during critical illness. Crit Care 19(1):284

35. Krysko DV, Agostinis P, Krysko O, Garg AD, Bachert C, Lambrecht BN, Vandenabeele P (2011) Emerging role of damage-associated molecular patterns derived from mitochondria in inflammation. Trends Immunol 32(4):157-164

36. Kang R, Chen R, Zhang Q, Hou W, Wu S, Cao L, Huang J, Yu Y, Fan XG, Yan Z et al (2014) HMGB1 in health and disease. Mol Aspects Med 40:1-116

37. Beurskens CJ, Aslami H, Kuipers MT, Horn J, Vroom MB, van Kuilenburg AB, Roelofs JJ, Schultz MJ, Juffermans NP (2012) Induced hypothermia is protective in a rat model of pneumococcal pneumonia associated with increased adenosine triphosphate availability and turnover*. Crit Care Med 40(3):919-926

38. Thiel M, Chouker A, Ohta A, Jackson E, Caldwell C, Smith P, Lukashev D, Bittmann I, Sitkovsky MV (2005) Oxygenation inhibits the physiological tissue-protecting mechanism and thereby exacerbates acute inflammatory lung injury. PLoS Biol 3(6):e174

39. Nagato AC, Bezerra FS, Talvani A, Aarestrup BJ, Aarestrup FM (2015) Hyperoxia promotes polarization of the immune response in ovalbumin-induced airway inflammation, leading to a TH17 cell phenotype. Immun Inflamm Dis 3(3):321-337

40. Waisman D, Brod V, Rahat MA, Amit-Cohen BC, Lahat N, Rimar D, Menn-Josephy H, David M, Lavon O, Cavari Y et al (2012) Dose-related effects of hyperoxia on the lung inflammatory response in septic rats. Shock 37(1):95-102

41. Waisman D, Brod V, Wolff R, Sabo E, Chernin M, Weintraub Z, Rotschild A, Bitterman H (2003) Effects of hyperoxia on local and remote microcirculatory inflammatory response after splanchnic ischemia and reperfusion. Am J Physiol Heart Circ Physiol 285(2):H643-652

42. Kiers D, Gerretsen J, Janssen E, John A, Groeneveld R, van der Hoeven JG, Scheffer G-J, Pickkers P, Kox M (2015) Short-term hyperoxia does not exert immunologic effects during experimental murine and human endotoxemia. Sci Rep 5:17441

43. Bailey TC, Maruscak AA, Martin EL, Forbes AR, Petersen A, McCaig LA, Yao L, Lewis JF, Veldhuizen RA (2008) The effects of long-term conventional mechanical ventilation on the lungs of adult rats. Crit Care Med 36(8):2381-2387

44. Lutz D, Gazdhar A, Lopez-Rodriguez E, Ruppert C, Mahavadi P, Gunther A, Klepetko W, Bates JH, Smith B, Geiser T et al (2015) Alveolar derecruitment and collapse induration as crucial mechanisms in lung injury and fibrosis. Am J Respir Cell Mol Biol 52(2):232-243

45. Bara M, Joffe AR (2014) The methodological quality of animal research in critical care: the public face of science. Ann Intensive Care 4:26

46. Zosky GR, Janosi TZ, Adamicza A, Bozanich EM, Cannizzaro V, Larcombe AN, Turner DJ, Sly PD, Hantos Z (2008) The bimodal quasi-static and dynamic elastance of the murine lung. J Appl Physiol (1985) 105(2):685-692

47. Seok J, Warren HS, Cuenca AG, Mindrinos MN, Baker HV, Xu W, Richards DR, McDonald-Smith GP, Gao H, Hennessy L et al (2013) Genomic responses in mouse models poorly mimic human inflammatory diseases. Proc Natl Acad Sci U S A 110(9):3507-3512

48. Fernandez R, Gili G, Villagra A, Lopez-Aguilar J, Artigas A (2013) Assessment of the inflammatory effect of low-dose oxygen in mechanically ventilated patients. Intensive Care Med 39(4):711-716

49. Ronchi JA, Figueira TR, Ravagnani FG, Oliveira HC, Vercesi AE, Castilho RF (2013) A spontaneous mutation in the nicotinamide nucleotide transhydrogenase gene of $\mathrm{C} 57 \mathrm{BL} / 6 \mathrm{~J}$ mice results in mitochondrial redox abnormalities. Free Radic Biol Med 63:446-456

Submit your manuscript to a SpringerOpen ${ }^{\circ}$ journal and benefit from:

- Convenient online submission

- Rigorous peer review

- Open access: articles freely available online

- High visibility within the field

Retaining the copyright to your article

Submit your next manuscript at $>$ springeropen.com 